\title{
Research on Application and Benefits of Energy Storage Systems
}

\author{
Nana $\mathrm{Li}^{1}$, Jing $\mathrm{Wu}^{2}$, Qionghui $\mathrm{Li}^{1}$, Jing $\mathrm{Hu}^{1}$, Hao Fan ${ }^{2}$, Bibin Huang ${ }^{1}$ \\ ${ }^{1}$ State Grid Energy Research Institute Co., Ltd., Beijing 102209, China \\ ${ }^{2}$ State Grid Corporation of China, Beijing, 100017, China
}

\begin{abstract}
At present, Energy storage systems are widely used in power supply, power grid and end-users system. There have been extensive application explorations in most application scenarios in China, such as smoothing power fluctuation and output tracking of new energy sources, assisting conventional units to participate in frequency modulation, peak-shaving frequency modulation of the power grid, system standby, peak-valley arbitrage of the load side, as well as demand reduction. This paper firstly investigates the typical operation modes of energy storage applied to new energy consumption scenarios, and analyzes three important technical approaches in order to promote new energy consumption, such as energy storage to stabilize fluctuation, tracking output and peak load balancing. Secondly, to evaluate the economic benefits of energy storage allocation in new energy projects in different regions of China by using the self-developed software for economic analysis of new energy and comprehensive energy system; thereafter the strategic suggestions for energy storage allocation in different regions are proposed. The results show that it is economical for wind power owners to build Pumped Thermal Energy Storage (PTES) and it is even cheaper to purchase PTES by wind power owners than to build electrochemical energy storage (EES) batteries by users when the same conditions of energy storage applies. Owner-built and owner-allocated Photovoltaic (PV) power station is poor in economy. Under the same energy storage condition, when the allocated energy of $1 \mathrm{MW}$ PV power generation is less than $200 \mathrm{~kW}$, EES is relatively more economical than PTES.
\end{abstract}

Key words: energy storage, new energy consumption, operation mode, economy measurement and calculation.

\section{Introduction}

Energy storage is an important component and key supporting technology of "internet plus" smart energy. With the development of electrochemical energy storage technology and cost reduction, energy storage has progressed rapidly in the application of end-user side, power grid side, grid-connected renewable energy, power auxiliary service and so on. From the perspective of energy storage scale, current energy storage projects in China mainly adopt PPES, followed by EES. According to the incomplete statistics of China Energy Research Society, CERS/Global Energy Storage Alliance (GESA), China Energy Storage Alliance (CNESA) global energy storage project library, by the end of 2020, the cumulative installed capacity of energy storage projects in China was $35.6 \mathrm{GW}$, accounting for $18.6 \%$ of the global energy storage market, with a year-on-year growth of $9.8 \%$. Among all EES technologies, the cumulative installed capacity of li-ion batteries is the highest with 2,902.4MW; molten salt thermal storage system ranked third, with a cumulative installed capacity of 520MW, up $23.8 \%$ year- on-year. From the distribution of energy storage applications, at present, the cumulative installed capacity of the power supply side of EES projects that have been put into operation in China is the highest, surpassing that of the user side for the first time. By the end of 2020, the cumulative scale of EES in China was $47.5 \%, 17.9 \%$ and $34.6 \%$ on the power supply side (including new energy generation side, combined auxiliary services of thermal power plants), the power grid side and the user side, respectively. Among EES projects newly put into operation in 2020, the installed capacity of new energy generation side projects takes the largest share, accounting for $50 \%$ [1-2].

This paper mainly studies the typical operation modes of energy storage used in new energy consumption scenarios, and analyzes three important technical approaches to promote new energy consumption, such as energy storage to stabilize fluctuations, tracking output and peak load balancing. On this basis, the self-developed economic analysis software of new energy and comprehensive energy system is used to conduct the economic benefit analysis of energy storage allocation in new energy 
projects in different regions of China; thereafter, the strategic suggestions for energy storage allocation in different regions are proposed.

\section{Typical operation modes of energy storage to promote new energy consumption}

Stabilizing fluctuation, tracking output and peak load balancing are three important technical approaches to improve the operation modes of new energy consumption. Inevitably, the large-scale centralized integration of new energy into the grid will bring many challenges to the operation and regulation of the power system. The inherent properties of new energy, such as randomness, fluctuation, and intermittence, are in urgent need of largescale energy storage to realize smoothing and tracking to enhance the friendliness of new energy to the power grid [3].

\subsection{Stabilizing fluctuation}

Time scale and fluctuation amplitude are the limiting indicators of the system to the fluctuation of new energy power. Therefore, the selection of energy storage types should focus on the performance of power characteristics of the types on the time scale of fluctuation limiting indicators. Power transmission companies in various countries usually have different indicators of maximum power fluctuation for grid-connected wind farms on time scale, and the fluctuation requirements are shown in Table 1.

Table 1 Maximum power fluctuation requirements for gridconnected wind farms in different countries

\begin{tabular}{|c|c|c|}
\hline Country & $\begin{array}{l}\text { Compan } \\
\mathrm{y}\end{array}$ & Climbing rate standard \\
\hline US & $\begin{array}{l}\text { FERC, } \\
\text { WECC }\end{array}$ & $\begin{array}{l}\text { ERCOT limits the } 1-\text { minute climbing } \\
\text { rate to less than } 10 \% \text { of installed } \\
\text { capacity. }\end{array}$ \\
\hline Canada & AESO & $\begin{array}{l}\text { Less than } 10 \% \text { installed capacity in } 1 \\
\text { minute }\end{array}$ \\
\hline$\underset{\mathrm{k}}{\text { Denmar }}$ & $\begin{array}{l}\text { Eltra\&E } \\
\text { lkraft }\end{array}$ & $\begin{array}{c}\text { Less than } 5 \% \text { installed capacity in } 1 \\
\text { minute: adjustable from } 10 \% \text { to } 100 \% \\
\text { per minute. }\end{array}$ \\
\hline $\begin{array}{c}\text { German } \\
y\end{array}$ & $\begin{array}{l}\text { E.ON } \\
\text { EnBW }\end{array}$ & $\begin{array}{c}\text { Less than } 10 \% \text { of installed capacity in } \\
1 \text { minute after startup }\end{array}$ \\
\hline UK & Soni & $\begin{array}{c}\text { Less than } 10 \mathrm{MW} \text { in } 1 \text { minute and the } \\
1 \text {-minute climbing rate not higher than } \\
3 \text { times of the average climbing rate in } \\
10 \text { minutes. }\end{array}$ \\
\hline Ireland & $\begin{array}{l}\text { EITGRI } \\
\text { D }\end{array}$ & $\begin{array}{l}\text { Less than } 30 \mathrm{MW} \text { within } 1 \mathrm{~min} \text { and with } \\
10 \mathrm{~min} \text {, and it can be operated } \\
\text { according to the real-time climbing } \\
\text { rate }(1-30 \mathrm{MW}) \text { required by power grid }\end{array}$ \\
\hline
\end{tabular}

\begin{tabular}{|c|c|c|c|c|}
\hline & ESBNG & $\begin{array}{c}\text { Installed } \\
\text { capacity < } \\
\text { 100MW: } \\
\text { Less than } \\
5 \% \text { of } \\
\text { installed } \\
\text { capacity } \\
\text { within 1min } \\
\text { (in any } \\
15 \mathrm{~min} \\
\text { period) } \\
\end{array}$ & $\begin{array}{c}\text { Installed } \\
\text { capacity < } \\
\text { 200MW: } \\
\text { Less than } \\
4 \% \text { of } \\
\text { installed } \\
\text { capacity } \\
\text { in 1min } \\
\text { (in any } \\
15 \mathrm{~min} \\
\text { period) }\end{array}$ & $\begin{array}{c}\text { Installed } \\
\text { capacity }> \\
200 \mathrm{MW} \text { : } \\
\text { Less than } \\
2 \% \text { of } \\
\text { installed } \\
\text { capacity } \\
\text { in } 1 \mathrm{~min} \\
\text { (in any } \\
15 \mathrm{~min} \\
\text { period) } \\
\end{array}$ \\
\hline $\begin{array}{l}\text { South } \\
\text { Africa }\end{array}$ & RSA & \multicolumn{3}{|c|}{ Less than $50 \mathrm{MW}$ in $1 \mathrm{~min}$} \\
\hline China & $\begin{array}{l}\text { State } \\
\text { Grid }\end{array}$ & $\begin{array}{c}\text { Installed } \\
\text { capacity < } \\
\text { 30MW: } \\
\text { Less than } \\
3 \mathrm{MW} \\
\text { change } \\
\text { within } \\
\text { 1min; Less } \\
\text { than 10MW } \\
\text { change in } \\
\text { 10min }\end{array}$ & $\begin{array}{c}30 \mathrm{MW}< \\
\text { installed } \\
\text { capacity }< \\
100 \mathrm{MW}: \\
\text { Less than } \\
1 / 10 \text { of } \\
\text { the } \\
\text { installed } \\
\text { capacity } \\
\text { within } \\
1 \mathrm{~min} ; \\
\text { Less than } \\
1 / 3 \\
\text { installed } \\
\text { capacity } \\
\text { within } \\
10 \mathrm{~min}\end{array}$ & $\begin{array}{c}\text { Installed } \\
\text { capacity > } \\
150 \mathrm{MW}: \\
\text { Within } \\
\text { 1min, the } \\
\text { change is } \\
\text { less than } \\
15 \mathrm{MW} ; \\
\text { Less than } \\
10 \mathrm{MW} \\
\text { change in } \\
10 \mathrm{~min}\end{array}$ \\
\hline
\end{tabular}

Fluctuations of new energy power in different time scales will create different impacts on system standby, energy dispatching and safe operation, etc. and can be reduced by energy storage to stabilize fluctuations, thus improving the power quality of new energy grid. Taking the PV energy storage combined power generation as an example, the energy storage in the optical storage combined dispatching system controls the output of the energy storage system according to the set smooth range to stabilize the fluctuation of PV output, and achieves the goal of controlling the fluctuation of PV output within the specified range in multiple time scales. Taking a 50MW PV power station as an example, the output fluctuation rate within 10 minutes can be less than $10 \%$ by combined energy storage [4].

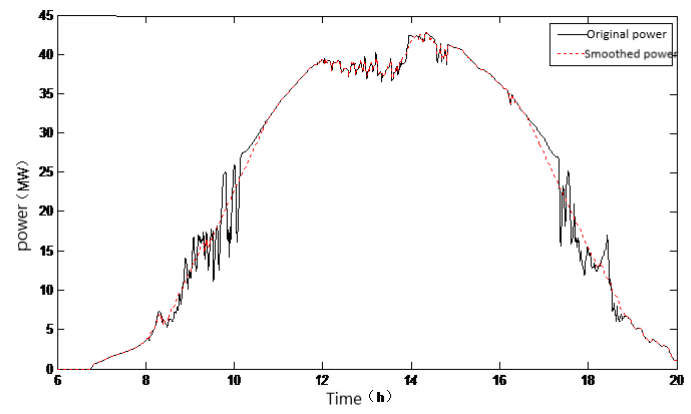

Figure 1 Smoothing fluctuation of PV (a) 


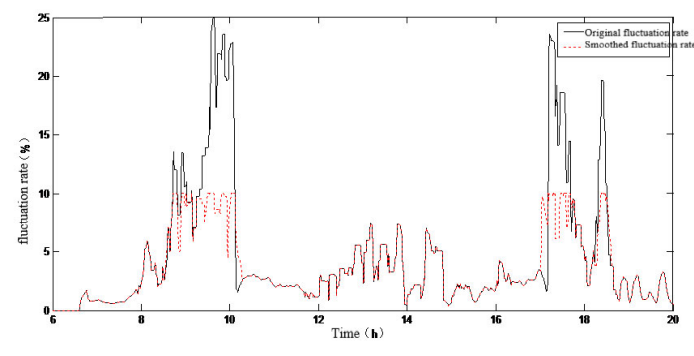

Figure 2 Smoothing fluctuation of PV (b)

The allocation of energy storage system to smooth out fluctuation requires comprehensive consideration including fluctuation limit indicators, characteristics of energy storage types, control methods of fluctuation smoothing control and energy management. The goal of the allocation is to minimize energy storage power and capacity while meeting system requirements. At present, the existing power and capacity allocation methods of energy storage systems are mainly based on theoretical analysis and simulation analysis. In general, an allocation method based on theoretical analysis is to analyze and extracts the characteristics of wind power fluctuation based on historical data at first instance, and follow by estimating the power and capacity of energy storage according to the characteristics of power fluctuation (such as maximum fluctuation, time scale, etc.). Whereas, an allocation method based on simulation analysis is generally based on massive typical wind power data. The existing fluctuation control and energy management methods are used to simulate and analyze the effect of the fluctuation control, and finally the minimum energy storage power and capacity required while meeting the fluctuation limit indicators are obtained.

\subsection{Tracking output}

In order to meet the stability of the output power of the combined power generation, tracking planned output is applied to ensure the actual output of the combined power generation system of new energy and energy storage as close as possible to the power generation plan curve based on the planned tracking error and energy state of energy storage through the charging and discharging of energy storage. According to the predicted output of new energy, the output of traditional units, the load demand, the operating state constraints and costs of each unit, the power grid dispatching body formulates the output curve of the new energy storage joint plan and sends it to new energy stations, which make coordinated control to track the output curve, which in fact, compensates the difference between the actual power of the combined power generation system and the planned curve in real time. At the same time, according to the feedback value of current battery power and battery remaining capacity, the maximum working capacity of the energy storage system is determined, and the information of the current allowable use capacity of the energy storage system and the current available maximum charge and discharge capacities are sent to the dispatching side, and requests the joint dispatching system to adjust the relevant control quantities. Figure 3 is a block diagram of the control strategy for tracking planned output. When the remaining capacity of the energy storage battery is close to overcharging, and the combined output is still higher than the planned value of power generation, a request for limiting power generation is sent to the combined dispatching system. When the remaining capacity of the energy storage battery is close to over discharging, and the combined output is still lower than the planned value of power generation, it sends the maximum working capacity of the energy storage system to the joint dispatching system, and requests the joint dispatching system to adjust the control strategy [5].

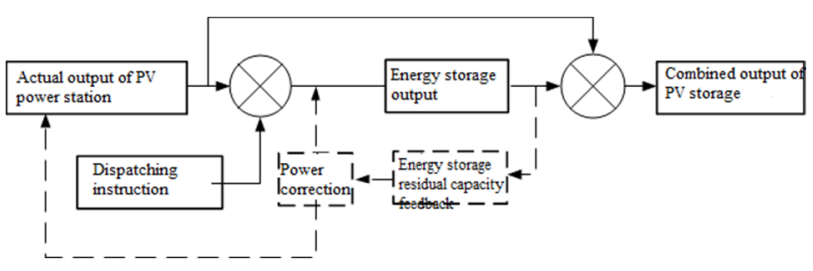

Figure 3 Control strategy for tracking planed output

\subsection{Peak load balancing}

New energy resources such as wind power and PV power have intermittent nature. Through the joint operation of energy storage and wind power or PV power, the electricity quantity of the new energy resources during the power-off period can be shifted in time, and the absorptive capacity of the system can be improved. When energy storage is operated in combination with wind power, energy storage absorbs the wind power output during the limited wind period and releases it during the non-limited wind power period, thus improving the profits of the joint system. The energy storage system discharges power when the wind power is lower than the power limit. At this stage, the energy storage system will be out of service after discharging the charged power, and it will not be put into use again until the upper limit of wind power output rises above the power limit again or the power limit is cancelled. When energy storage works in conjunction with PV, energy storage can store the excess power generated by PV during the day and release it to the load at night. When the energy storage is insufficient, it will supply power to the load by means of commercial power [6].

In the background of Energy Internet (EI), shared energy storage is a new-generation energy storage concept which has the advantages of wide distribution and flexible application and can effectively improve the stability characteristics of power grid and the absorptive capacity of new energy. Taking the Qinghai Shared Energy Storage project as an example, during the peak PV period from 10:00 to 16:00 on the same day, Longyuan Golmud PV Power Station and SDIC Huajing Golmud PV Power Station use the originally discarded PV power to charge the energy storage systems, reducing the discarded PV power and improving the absorptive capacity of the power systems for new energy; During the period of 19:00-21:00 
at night, the energy storage power stations discharge at a constant power, and the PV power stations and the energy storage power stations share the grid-connected power generation income of the energy storage power stations during this period.

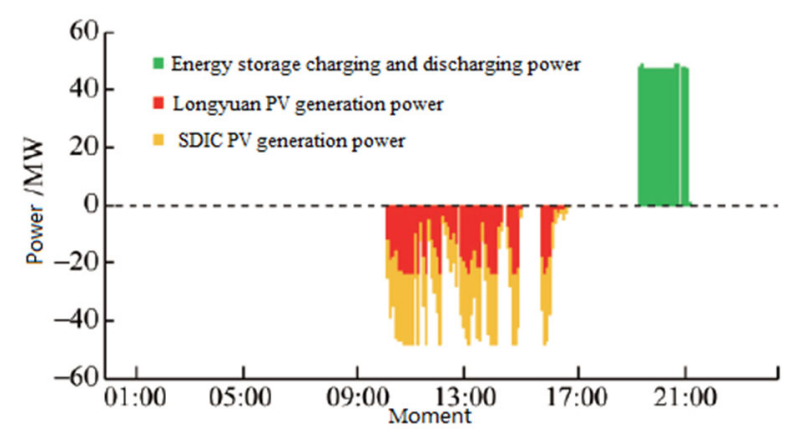

Figure 4 Charging and discharging operations of Qinghai Shared Energy Storage (a)

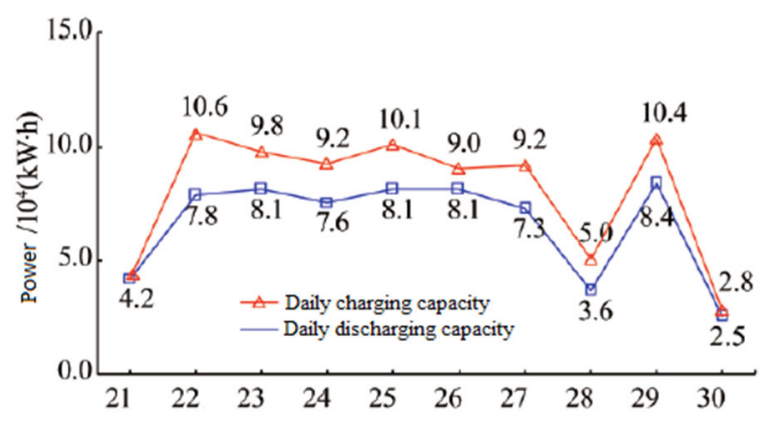

Figure 5 Charging and discharging operations of Qinghai Shared Energy Storage (b)

The principle for energy storage allocation of PV power plants is different from that of wind farms under peak load balancing, and wind power has higher requirements for energy storage capacity and duration. If a PV power station is equipped with the energy storage with $10 \%$ of its installed capacity and 4 hours of continuous discharge, the maximum PV abandonment rate can be reduced by $5 \%$. For some wind farms that have been abandoned for a long period of time continuously, it is necessary to allocate an energy storage system with the installed capacity of about $20 \%$, which requires higher duration of continuous discharging. If the complementary characteristics of wind power and PV power are comprehensively considered, the joint allocation of energy storage can appropriately reduce the demand for energy storage capacity [7-8].

\section{Economic Analysis of "New Energy + Energy Storage"}

\subsection{New Energy and IES Economic Analysis software}

The New Energy and IES Economic Analysis (NEIESEA) software is independently designed and developed by
State Grid Energy Research Institute Co., Ltd., with completely independent intellectual property rights. The NEIESEA was designed and developed strictly in accordance with the standards of large-scale software projects, applying the object-oriented thought and the high-level language $\mathrm{C}++$ to develop the core algorithms, and ensuring the encapsulation, inheritance and polymorphism of the software, and $\mathrm{C \#}$ was used to develop the interface. The main functions of the NEIESEA include power supply (PV, wind power, natural gas, biogas, biomass), energy storage, energy network (power grid, heating network) and economic analysis of energy conversion equipment (heat pumps, electric boilers, ice storage). IES Economic Analysis; economic analysis of new energy in China. This paper uses NEIESEA software to analyze and evaluate the energy storage economy of new energy allocation [9-11].

\subsection{Economic analysis of owner-built energy storage technologies}

Owner-built energy storage is relatively cost effective. According to the investment cost of onshore wind power in each province in 2020 (average investment cost: RMB6,900/kW) and the benchmark power price of wind power in 2018 (connected to the grid before the end of 2020), investment cost of lithium iron phosphate battery: RMB1,900/kWh, calculated according to the assumption of being replaced twice on a 10 -year and 20 -year basis. If the wind farms are equipped with $10 \%$ lithium iron phosphate batteries for one hour (energy: $100 \mathrm{kWh}$ ), the national average internal rate of return (IRR) is $9.2 \%$, and the IRR of projects in 21 provinces and regions including Fujian, Gansu, Liaoning, Sichuan, Jiangsu, Hubei, Tibet, Shandong, Anhui, Hunan, Heilongjiang, southern Hebei, Jiangxi, Beijing, Zhejiang, Shanxi, Tianjin, Yunnan, and Shanghai exceeds $8 \%$. If the wind farms are equipped with $20 \%$ lithium iron phosphate batteries (energy 200) for one hour, the national average IRR is $8.6 \%$, and the IRR of 19 provinces and regions including Fujian, Gansu, Liaoning, Sichuan, Jiangsu, Hubei, Tibet, Shandong, Anhui, Hunan, Heilongjiang, southern Hebei, Jiangxi, Beijing, Zhejiang, Shanxi, Tianjin, Yunnan, and Shanghai exceeds $8 \%$. If the wind farms are equipped with $20 \%$ lithium iron phosphate batteries for 2 hours (10\% lithium iron phosphate batteries for 4 hours) (energy $400 \mathrm{kWh}$ ), the national average IRR is $7.7 \%$, and the IRR of projects in 14 provinces and regions including Fujian, Gansu, Liaoning, Sichuan, Jiangsu, Hubei, Tibet, Shandong, Anhui, Hunan, Heilongjiang, southern Hebei, Jiangxi, and Beijing still exceeds $8 \%$. If the wind farms are equipped with $20 \%$ proportion of 4-hour lithium iron phosphate batteries (energy: $800 \mathrm{kWh}$ ), the national average IRR is $6.0 \%$, and the IRR of projects in seven provinces and regions including Fujian, Liaoning, Gansu, Sichuan, Tibet, Jiangsu, and Hubei still exceeds $8 \%$. 
Table 2 Economic comparison of owner-built energy storage of wind power owners

\begin{tabular}{ccccc}
\hline \multicolumn{2}{c}{ Energy storage allocation strategy } & \multicolumn{2}{c}{ IRR } \\
\hline $\begin{array}{c}\text { Proportion } \\
\text { of new } \\
\text { energy } \\
\text { installed } \\
\text { capacity }\end{array}$ & $\begin{array}{c}\text { Energy } \\
\text { (1MW fan } \\
\text { as an } \\
\text { example) }\end{array}$ & $\begin{array}{c}\text { National } \\
\text { average } \\
\text { of } \\
\text { provinces } \\
\text { and } \\
\text { regions } \\
\text { higher } \\
\text { than } 8 \%\end{array}$ \\
\hline NA & NA & 0 & $9.8 \%$ & 22 \\
\hline $10 \%$ & 1 hour & $100 \mathrm{kWh}$ & $9.2 \%$ & 21 \\
\hline $20 \%$ & 1 hour & $200 \mathrm{kWh}$ & $8.6 \%$ & 19 \\
\hline $10 \%$ & 2 hours & $200 \mathrm{kWh}$ & & \\
\hline $20 \%$ & 2 hours & $400 \mathrm{kWh}$ & & \\
\hline $10 \%$ & 4 hours & $400 \mathrm{kWh}$ & $7.7 \%$ & 14 \\
\hline $20 \%$ & 4 hours & $800 \mathrm{kWh}$ & $6.0 \%$ & 7 \\
\hline
\end{tabular}

Owner-built energy storage of PV power generation owners is less cost effective. According to the provincial centralized PV power investment cost in 2020 (average investment: RMB3,800/kW) and the benchmark PV power price in 2018, the investment cost of lithium iron phosphate battery system is 1,900 yuan/kilowatt-hour, which will be replaced twice after 10 and 20 years. If the PV power station is equipped with $10 \%$ lithium iron phosphate batteries for one hour, the national average internal rate of return is $6.6 \%$, and the IRR of projects in Tibet, eastern Inner Mongolia, Shandong, northern Hebei, Shanxi, and Qinghai alone exceeds 8\%. If the PV power station is equipped with $10 \%$ lithium iron phosphate batteries for 4 hours, the national average IRR is $4.3 \%$, and the IRR of projects in all provinces is less than $8 \%$ [12].

Figure 3 Economic comparison of owner-built energy storage of $\mathrm{PV}$ power owners

\begin{tabular}{ccccc}
\hline \multicolumn{2}{c}{ Energy storage allocation strategy } & \multicolumn{2}{c}{ IRR } \\
\hline $\begin{array}{c}\text { Proportion } \\
\text { of new } \\
\text { energy } \\
\text { installed } \\
\text { capacity }\end{array}$ & Duration & $\begin{array}{c}\text { Energy } \\
\text { (1MW PV } \\
\text { as an } \\
\text { example) }\end{array}$ & $\begin{array}{c}\text { National } \\
\text { average }\end{array}$ & $\begin{array}{c}\text { Number of } \\
\text { provinces } \\
\text { and } \\
\text { regions } \\
\text { higher } \\
\text { than } 8 \%\end{array}$ \\
\hline NA & NA & 0 & $7.5 \%$ & 15 \\
\hline $10 \%$ & 1 hour & $100 \mathrm{kwh}$ & $6.6 \%$ & 6 \\
\hline $20 \%$ & 1 hour & $200 \mathrm{kWh}$ & $5.7 \%$ & 3 \\
\hline $10 \%$ & 4 hours & $400 \mathrm{kWh}$ & $4.3 \%$ & 0 \\
\hline $20 \%$ & 4 hours & $800 \mathrm{kWh}$ & $2.4 \%$ & 0 \\
\hline
\end{tabular}

\subsection{Economic analysis of energy storage capacity purchased by new energy owners}

Purchased wind power PTES capacity is relatively cost effective. According to the investment cost of onshore wind power in each province in 2020 (average investment cost: RMB6,900/kW) and the benchmark power price of wind power in 2018 (connected to the grid before the end of 2020), the annual unit kilowatt cost for purchased pumped storage is RMB600 (energy: $6 \mathrm{kWh}$ ). If the wind farms buy pumped storage energy of $1.67 \%$ capacity (energy: $100 \mathrm{kWh}$ ), the national average IRR is $8.7 \%$, and the IRR of projects in 17 provinces and regions including Gansu, Liaoning, Fujian, Sichuan, Jiangsu, Hubei, Shandong, Tibet, Anhui, Hunan, Heilongjiang, southern Hebei, Jiangxi, Beijing, Zhejiang, Tianjin, and Shanxi exceeds $8 \%$. If $3.33 \%$ capacity (energy $200 \mathrm{kWh}$ ) pumped storage energy is purchased by wind farm, the national average IRR is $8.5 \%$, and the IRR of projects in 16 provinces and regions including Gansu, Liaoning, Fujian, Sichuan, Jiangsu, Hubei, Shandong, Tibet, Anhui, Hunan, Heilongjiang, southern Hebei, Jiangxi, Beijing, Zhejiang, and Tianjin exceeds $8 \%$. If the wind farm purchases $6.66 \%$ capacity (energy $400 \mathrm{kWh}$ ) pumped storage energy, the national average IRR is $8.2 \%$, and the IRR of projects in 15 provinces and regions including Gansu, Liaoning, Fujian, Sichuan, Jiangsu, Hubei, Shandong, Tibet, Anhui, Hunan, Heilongjiang, southern Hebei, Jiangxi, Beijing, and Zhejiang exceeds $8 \%$. If $13.34 \%$ capacity (energy 800 $\mathrm{kWh}$ ) pumped storage energy is purchased by wind farm, the national average IRR is $6.9 \%$, and the IRR of projects in 13 provinces and regions including Gansu, Liaoning, Fujian, Sichuan, Jiangsu, Hubei, Shandong, Tibet, Anhui, Hunan, Heilongjiang, southern Hebei, and Jiangxi still exceeds $8 \%$.

Figure 4 Economic comparison of purchased energy storage by wind power owners

\begin{tabular}{cccc}
\hline \multicolumn{2}{c}{$\begin{array}{c}\text { Energy storage allocation } \\
\text { strategy }\end{array}$} & \multicolumn{2}{c}{ IRR } \\
\hline $\begin{array}{c}\text { Proportion of } \\
\text { new energy } \\
\text { installed } \\
\text { capacity }\end{array}$ & $\begin{array}{c}\text { Energy (1MW } \\
\text { fan as an } \\
\text { example) }\end{array}$ & $\begin{array}{c}\text { National } \\
\text { average }\end{array}$ & $\begin{array}{c}\text { Number of } \\
\text { provinces and } \\
\text { regions higher } \\
\text { than } 8 \%\end{array}$ \\
\hline $1.67 \%$ & $100 \mathrm{kwh}$ & $8.7 \%$ & 17 \\
\hline $3.33 \%$ & $200 \mathrm{kWh}$ & $8.6 \%$ & 16 \\
\hline $6.67 \%$ & $400 \mathrm{kWh}$ & $8.2 \%$ & 15 \\
\hline $13.34 \%$ & $800 \mathrm{kWh}$ & $7.4 \%$ & 13 \\
\hline
\end{tabular}

It is not economical to purchase PV PHES capacity. According to the provincial centralized PV power investment cost in 2020 (average investment cost: $\mathrm{RMB} 3,800 / \mathrm{kW}$ ) and the benchmark PV power price in 2018 , if PV power stations purchase $10 \%$ capacity pumped storage energy storage, the national average IRR is $4.3 \%$, and the IRR of each provincial project does not exceed $8 \%$.

Figure 5 Economic comparison of purchased energy storage by PV owners

\begin{tabular}{cccc}
\hline $\begin{array}{c}\text { Energy storage allocation } \\
\text { strategy }\end{array}$ & \multicolumn{2}{c}{ IRR } \\
\hline $\begin{array}{c}\text { Proportion } \\
\text { of new } \\
\text { energy } \\
\text { installed } \\
\text { capacity }\end{array}$ & $\begin{array}{c}\text { Energy } \\
\text { (1MW PV as } \\
\text { an example) }\end{array}$ & $\begin{array}{c}\text { National } \\
\text { average }\end{array}$ & $\begin{array}{c}\text { Number of } \\
\text { provinces } \\
\text { and regions } \\
\text { higher than } \\
8 \%\end{array}$ \\
\hline $1.67 \%$ & $100 \mathrm{kWh}$ & $5.6 \%$ & four \\
\hline $3.33 \%$ & $200 \mathrm{kWh}$ & $5.3 \%$ & three \\
\hline $6.67 \%$ & $400 \mathrm{kWh}$ & $4.9 \%$ & 0 \\
\hline $13.34 \%$ & $800 \mathrm{kWh}$ & $4.3 \%$ & 0 \\
\hline
\end{tabular}


It is therefore evident that self-construction and allocation of PTES for wind power owners are economically viable. Under the same energy storage conditions, it is economical for wind power owners to purchase PTES services than building EES batteries by themselves. Owner-built and owner-allocated PTES is not profitable and sustainable. Under the same energy storage condition, when the allocated energy of $1 \mathrm{MW}$ PV power generation is less than $200 \mathrm{~kW}$, EES is relatively more economical than PTES.

\section{Conclusion}

The continuous development of energy storage technology and cost reduction drive growth of energy storage development in scale. Energy storage has diversified development trends in the fields of power grid side, power supply side, user side, power market and so on. This paper first studies the typical operation modes of energy storage applied to new energy consumption scenarios and analyzes three important technical approaches to promote new energy consumption, such as energy storage to stabilize fluctuation, tracking output and peak load balancing. Second, by using the self-developed software for economic analysis of new energy and comprehensive energy system, the economic benefits of energy storage allocation in new energy projects in different regions of China are analyzed, and the strategic suggestions for energy storage allocation in different regions are put forward. The results show that it is economical for wind power owners to build and Pumped Themes Energy Storage (PTES), and it is more economical to purchase PTES by wind power owners than to build electrochemical energy storage (EES) batteries by users under the same conditions of energy storage. Owner-built and owner-allocated PTES is less business viable. Under the same energy storage condition, when the allocated energy of $1 \mathrm{MW}$ PV power generation is less than $200 \mathrm{~kW}$, EES is relatively more economical than PTES

\section{Acknowledgments}

This work was financially supported by the Pre-project of State Grid Corporation of China "Research on key issues of new energy development and consumption"

\section{References}

1. Xu Shouping, Li Xiangjun, Hui Dong. Overview of development status and demonstration application of large-scale electrochemical energy storage systems [J]. Electric Power Construction, 2013(7):8.

2. XU Shouping, LI Xiangjun, Hui Dong. Overview of development status and demonstration application of large-scale electrochemical energy storage system [J]. Electric Power Construction, 2013.

3. Mu Kai, Zha Hao, Liu Jia, et al. Research on comprehensive technical measures to promote large- scale new energy consumption [J]. Energy of China, 2017, 39(8):5.

4. Yang Junfeng, Zheng Xiaoyu, Hui Dong, et al. Capacity demand analysis of energy storage technology to promote the consumption of new energy in transmission-side power grid [J]. Energy Storage Science and Technology, 2018, v.7; No.36(04):158-164.

5. Hu Yang, Ma Xiyuan, Lei Bo, et al. Feasibility study on energy storage to promote new energy consumption in areas of China Southern Power Grid [J]. Southern Power System Technology, 2018, 12(9):9.

6. Sun Jie, Kang Yiran, Han Yongqiang, Zhang Xiulu, Jin Hongyang. Coordinated optimization models of grid energy storage in regional multi-energy systems considering new energy consumption $[\mathrm{J}]$. Renewable Energy Resources, 2020, 38(11):6.

7. Bing Wang, Wang Nan, Li Na, et al. Study on the industrial policies of electrochemical energy storage for large-scale new energy grids [J]. Electrical \& Energy Management Technology, 2021(4):6.

8. Sun Fengjie, Ma Jing, Xu Jiayin, et al. Economy of battery energy storage systems with different investors [J]. Battery Bimonthly, 2018, 48(2):5.

9. Wang Jiali. "Sword of Damocles" of new energy distribution and energy storage $[\mathrm{J}]$. Energy, 2020(7):5.

10. Wang Jiali. Exploring new energy distribution and energy storage business model [J]. Energy, 2020(7):2.

11. Chen Minxi. Side A and side B of "new energy distribution and energy storage" [J]. China Power Enterprise Management, 2020(19):6.

12. Fan Baoji. Technical and economic analysis of China's new energy storage battery industry [D]. Journal of Jilin University, 2010. 